\title{
Investigation of Tribological Performances for Porous Structure of Diatom Frustule with FSI Method
}

\author{
Fanming Meng, Guixiang Gao, and TingTing Li \\ The State Key Laboratory of Mechanical Transmission, Chongqing University, Chongqing 400044, China \\ Correspondence should be addressed to Fanming Meng; fmmeng@xjtu.edu.cn
}

Received 28 December 2013; Accepted 29 January 2014; Published 17 March 2014

Academic Editor: Zaoyang Guo

Copyright (C) 2014 Fanming Meng et al. This is an open access article distributed under the Creative Commons Attribution License, which permits unrestricted use, distribution, and reproduction in any medium, provided the original work is properly cited.

Tribological performances of the diatom frustule are investigated with the liquid-solid interaction (FSI) method. Take, for example, the representative Coscinodiscus sp. shell; the diatom frustule with the porous structure is achieved by the scanning electron microscope (SEM). Based on the frustule, the representative diatom frustule is modeled. Further, tribological performances of the diatom at its different geometry sizes and velocities are solved with FSI method and compared with corresponding values for the nonporous structure. The numerical result shows that the existence of the porous structure of the diatom helps to reduce friction between it and ambient water and to increase its load-carrying capacity.

\section{Introduction}

A diatom is a single-celled organism, which is widely distributed in the sea water or freshwater. So far, over hundreds of thousands of species of diatoms have been found in the world [1]. The most striking feature of the diatom is its elaborate frustule made up of grotesque amorphous silicon. Considerable researches available show that the main cause that the diatom has not been eliminated in the past tens of millions of years [2-6] is due to superior mechanical properties of its frustule, which is attracting the intense attention of researchers. Kröger [7] observed through SEM that the different diatom frustules exhibit diversity in their shapes and sizes. Michels et al. [8] found through the experiment that the elaborately porous structure of the diatom can greatly reduce its damage probability in the sea water. Meanwhile, fruitful porous structures of the Coscinodiscus sp. and Thalassiosira eccentrica are found by Losic et al. through SEM [9]. Besides, an experiment result about $F$. kerguelensis from Hamm et al. [10] shows that this kind of diatom frustules have the elastic modulus as high as $22.4 \mathrm{GPa}$, with strong ability to restore the shell deformation. Almqvist et al. [11] pointed out that the high hardness and elastic modulus of the Navicula pelliculosa depend on its species. By imitating the porous structure of the diatom frustule, Jang et al. [12] created a three-dimensional hollow nanometer ceramic structure, whose tensile strength is as high as $1.75 \mathrm{GPa}$. Based on the molecular dynamics theory, Sen and Buehler [13] found that the toughness for every layer of the porous structure of the diatom ranges from $1.0 \times 10^{10}$ to $3.0 \times 10^{11} \mathrm{~J} / \mathrm{m}^{3}$. By comparison of the bending strengths for the specified four different diatoms, Young et al. [14] revealed that the bending strength varies due to the discrepancy in their morphologies. Another comparative study about the ductility, elasticity modulus, and toughness of the diatom silica shell was conducted by Garcia et al. [15]. They found that the above three values are up to $120 \%, 36 \mathrm{GPa}$, and $1.29 \mathrm{GJ} / \mathrm{m}^{3}$, respectively.

However, the above researches are mainly centralized on biological and mechanical properties of the diatom. So far, a very few researches of tribological performances for the diatom have been conducted. Gebeshuber et al. [16, 17] found that the self-lubrication of the diatom can significantly reduce its autologous friction and wear. Toyoda et al. $[18,19]$ pointed out that different tribological behaviors of the diatom are due to the diversity of its morphology structures. However, these tribological properties have been not well understood to date, especially the mechanism of lubrication and friction for the diatom frustule [20]. Therefore, it is necessary to explore this tribological mechanism. In the present work, the morphology structure of the representative Coscinodiscus sp. 


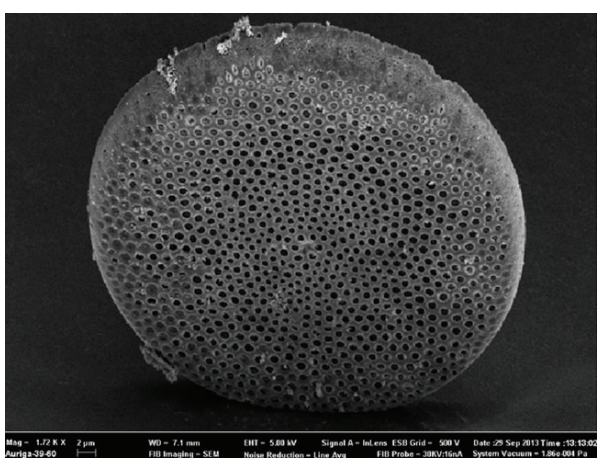

(a)



(b)

Figure 1: SEM images of the Coscinodiscus sp.: (a) SEM image of the whole Coscinodiscus sp. and (b) porous structure of the Coscinodiscus sp. frustule.

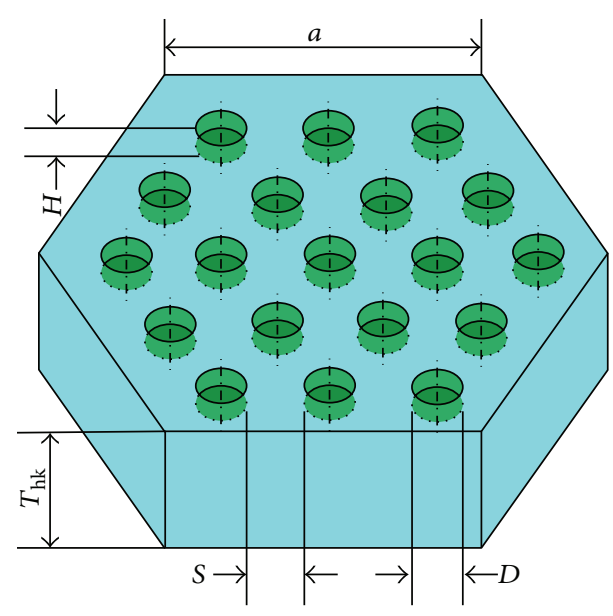

(a)

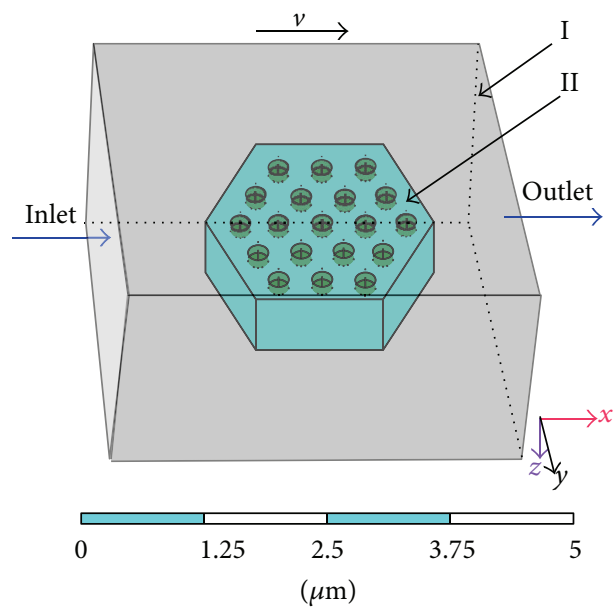

(b)

FIGURE 2: Calculating model: (a) basic unit of the Coscinodiscus sp. frustule and (b) boundary conditions.

is observed by SEM and its 3D model is established with Pro/E software based on the observed sample. Then tribological performances for the porous structure of the diatom frustule are simulated with FSI method through the CFX module of the commercial software ANSYS 14.5, in which the twoway coupling between the liquid and solid is considered simultaneously in solving the associated fluid or constitutive equations. Finally, the associated conclusions are drawn.

\section{Model}

2.1. Image Collection. To clearly observe the pores on the surface of the Coscinodiscus sp. by means of SEM, it is necessary to make the Coscinodiscus sp. sample have good electrical conductivity. For this, the authors make an ultrasonic treatment of the sample with TOAB (tetraoctyl ammonium bromide) and ethanol, as surface active agents, and then make a jetting gold on the sample. After this, the image collection is realized by means of ZEISS AURIGA dual beam system with the resolution of $1 \mathrm{~nm}$, where the diatom images collected under condition of normal temperature are shown in Figure 1. The image of the whole Coscinodiscus sp. at 1720 magnification is presented in Figure 1(a), while the porous frustule of the Coscinodiscus sp., obtained at magnification of $1.119 \times 10^{4}$ times, is shown in Figure 1(b). From Figure 1(b), one can observe that elaborate porous structures are distributed on the Coscinodiscus sp. frustule, in which case its tribological mechanism will be revealed in what follows.

2.2. Simulation Model. In the simulation, representative Coscinodiscus sp. frustule is used. The model of an elementary cell taken from this diatom frustule is established, as shown in Figure 2(a). In the model, the cell thickness $T_{\mathrm{hk}}$ along the $z$ direction is set to be $900 \mathrm{~nm}$. Around the geometry center of each unit, 19 pores are assumed to exist distributed in the form of hexagon with side length $a$ of $1.2 \times 10^{3} \mathrm{~nm}$. The symbols $D$ and $H$ represent the diameter and depth of the pore, respectively, and $S$ is the interval between two closely adjacent pores. In the solution, some boundary conditions need to be determined for the simulation, exhibited in Figure 2(b) where the displacement for the bottom surface 


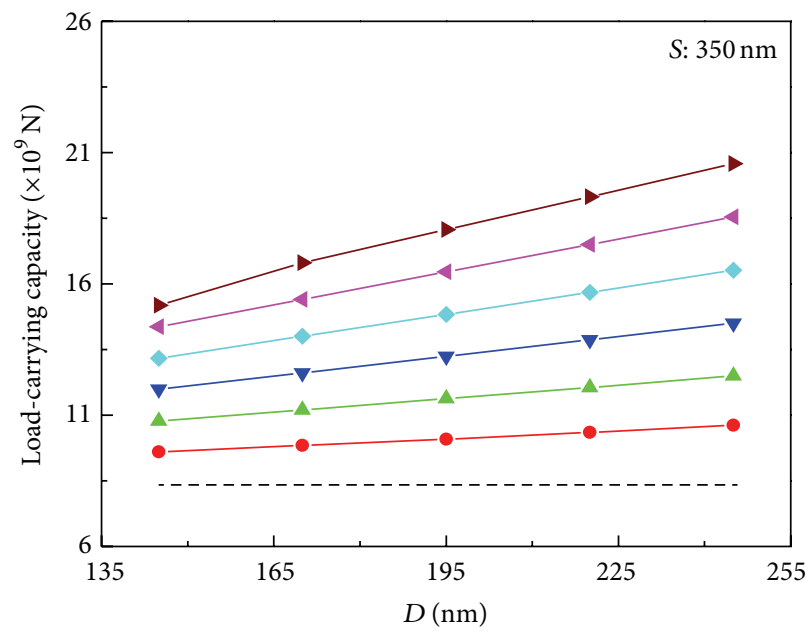

(a)

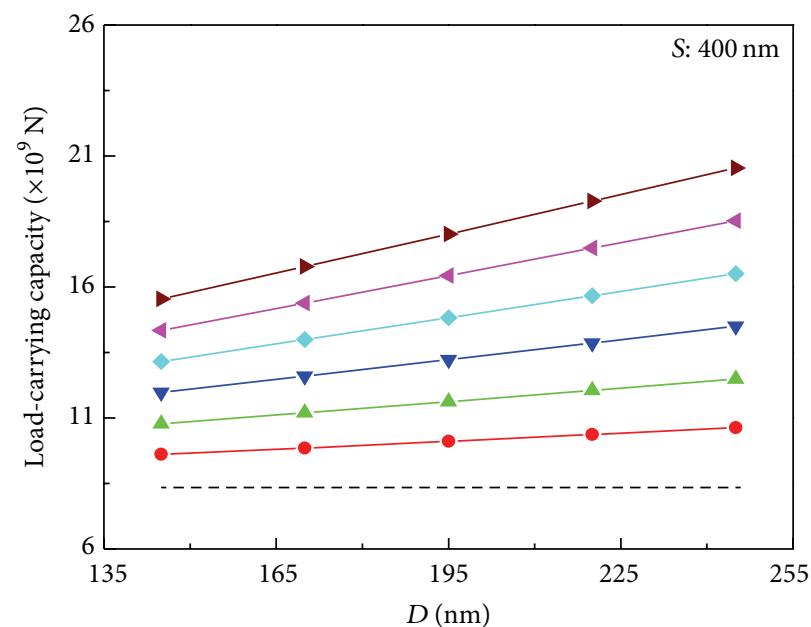

$$
\begin{array}{ll}
--- \text { Without pores } & -\triangleleft-H=200 \mathrm{~nm} \\
-\bullet-H=50 \mathrm{~nm} & \rightarrow-H=250 \mathrm{~nm} \\
-\triangle-H=100 \mathrm{~nm} & \rightarrow H=300 \mathrm{~nm} \\
-\checkmark-H=150 \mathrm{~nm} &
\end{array}
$$

(c)

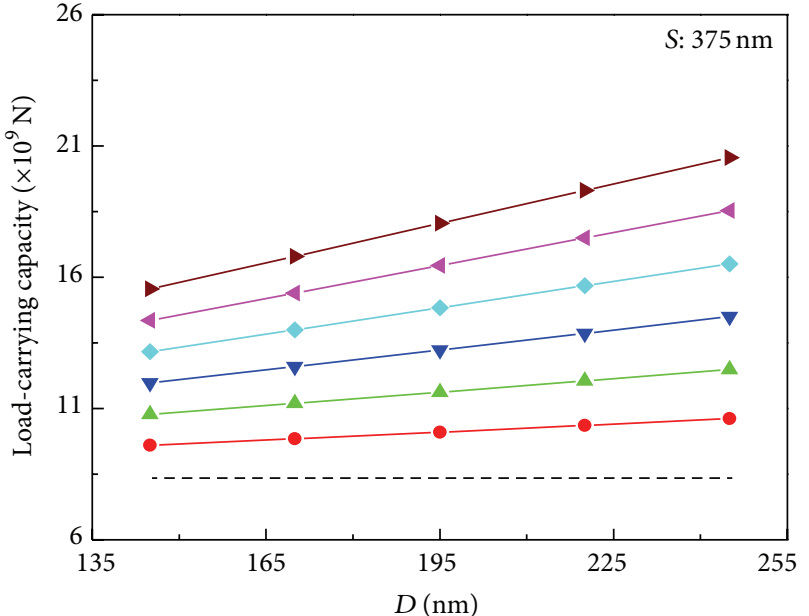

(b)

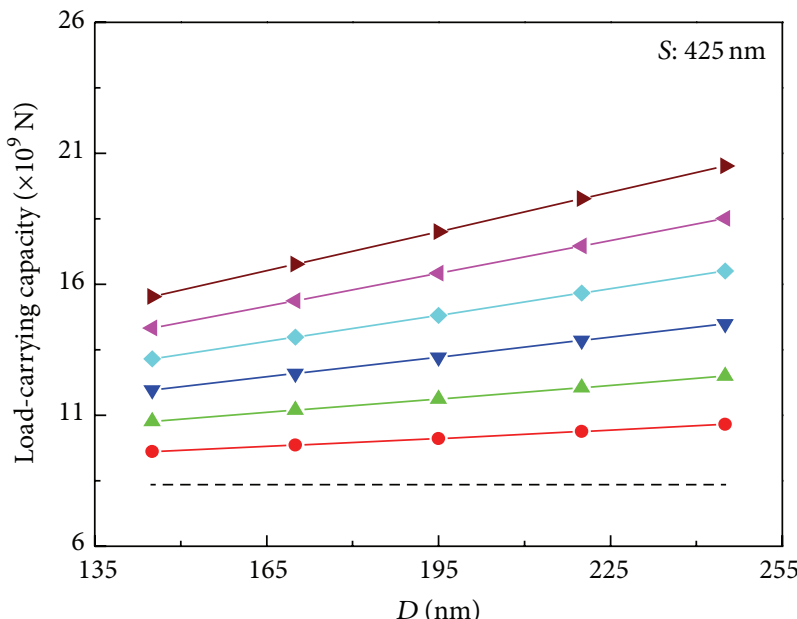

$$
\begin{array}{ll}
-- \text { Without pores } & -\triangleleft H=200 \mathrm{~nm} \\
-\bullet-H=50 \mathrm{~nm} & -\triangleleft-H=250 \mathrm{~nm} \\
-\triangle-H=100 \mathrm{~nm} & -\bullet-H=300 \mathrm{~nm} \\
-\mathbf{v}-H=150 \mathrm{~nm} &
\end{array}
$$

(d)

Figure 3: Load-carrying capacities at different pore diameters and depths of Coscinodiscus sp.: (a) at interval of $350 \mathrm{~nm}$, (b) at interval of $375 \mathrm{~nm}$, (c) at interval of $400 \mathrm{~nm}$, and (d) at interval of $425 \mathrm{~nm}$.

of the diatom is constrained along the $y$ - and $z$-axes. Meanwhile, arrow I indicates the water moving with the velocity $v_{f}$ along the positive $x$ direction, while arrow II stands for the Coscinodiscus sp. frustule moving with the velocity $v_{s}$ along the $x$ direction. Besides these, the elastic modulus, Poisson ratio, and density of the frustule are $73 \mathrm{GPa}, 0.17$, and $2500 \mathrm{Kg} / \mathrm{m}^{3}$, respectively. And the viscosity, specific heat, and density of the water are set to be $0.00105 \mathrm{~Pa} \cdot \mathrm{s}, 3890 \mathrm{~J} / \mathrm{Kg} / \mathrm{K}$, and $1025 \mathrm{Kg} / \mathrm{m}^{3}$, respectively.

\section{Governing Equations}

During the FSI analysis, the inflow and outflow of the water through the Coscinodiscus sp. frustule are identical in the mass, and thus the continuous equation describing the variation of the water can be used and is given below:

$$
\rho_{f} \nabla \cdot\left(v_{f}\right)=0
$$

where $\rho_{f}$ denotes the water density and $v_{f}$ are the velocity vectors in the $x, y$, and $z$ directions, among which the velocity in $x$ direction is $v_{f}$ stated previously.

Based on an assumption that lubricant is isothermal, laminar, and continuous, the Navier-Stokes equation used for describing the hydrodynamic action of the water is expressed as

$$
\rho_{f} \nabla \cdot\left(v_{f} v_{f}\right)=-\nabla p+\nabla \cdot \mu\left[\nabla v_{f}+\left(\nabla v_{f}\right)^{T}\right],
$$

where $p, \mu$, and $v_{f}$ denote the pressure, viscosity, and velocity of the water, respectively. $T$ is the transposition symbol. 


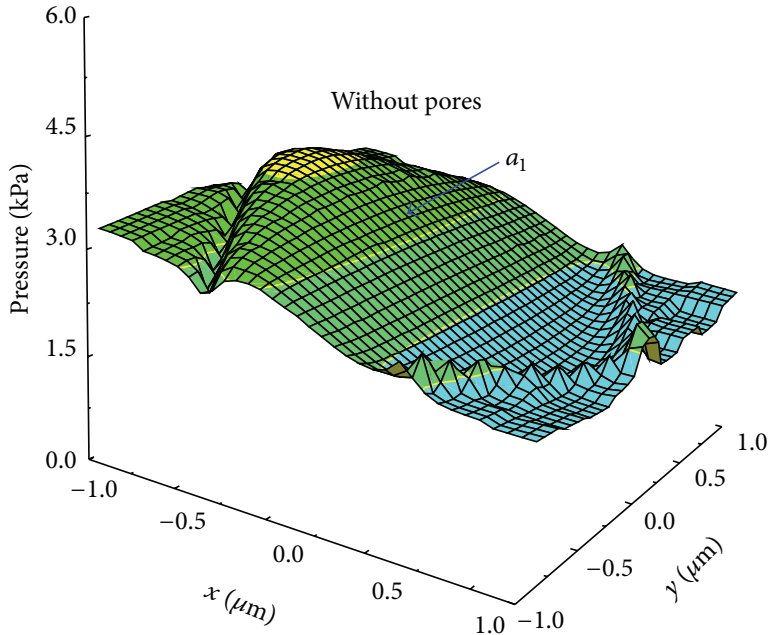

(a)

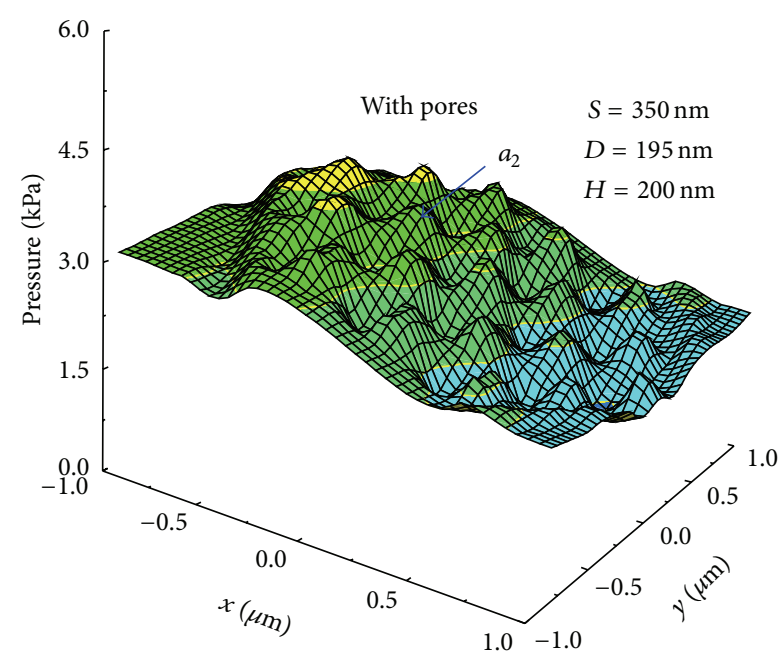

(b)

FIGURE 4: Pressures of Coscinodiscus sp. frustule with and without pores: (a) without pores and (b) with pores.



(a)

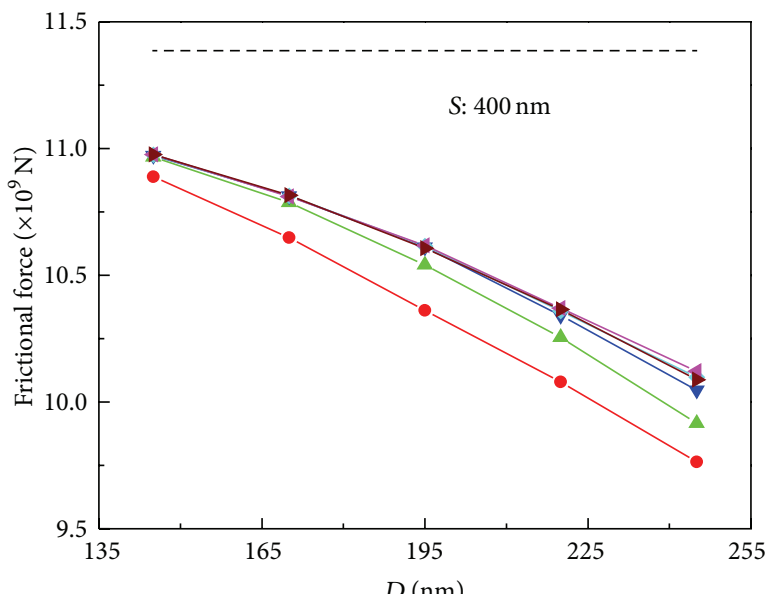

(c)

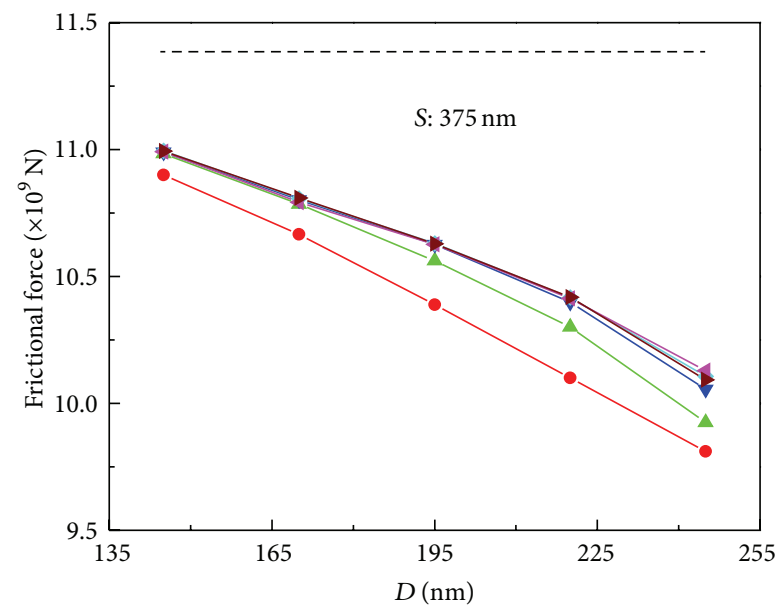

(b)


(d)

FIGURE 5: Frictional forces at different pore diameters and depths of Coscinodiscus sp.: (a) at interval of $350 \mathrm{~nm}$, (b) at interval of $375 \mathrm{~nm}$, (c) at interval of $400 \mathrm{~nm}$, and (d) at interval of $425 \mathrm{~nm}$. 




(a)



(c)

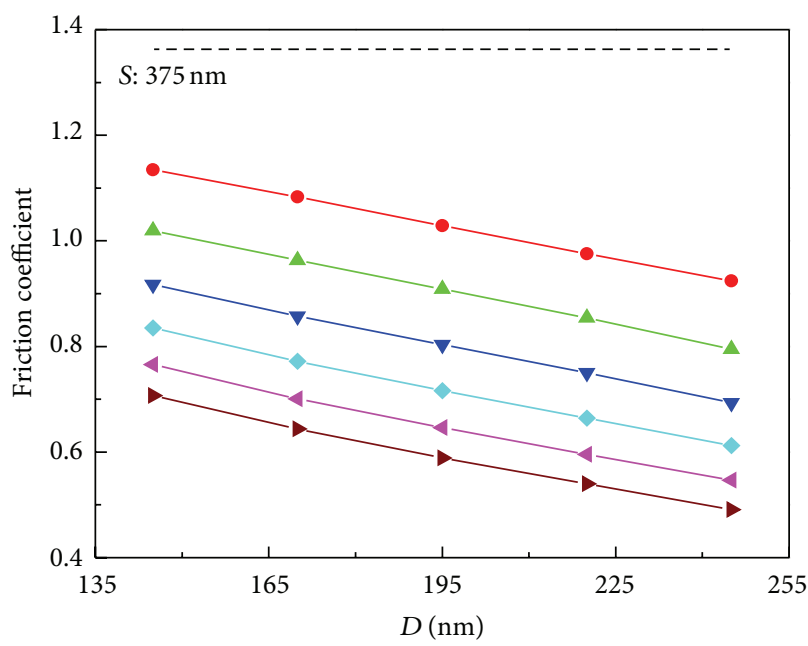

(b)

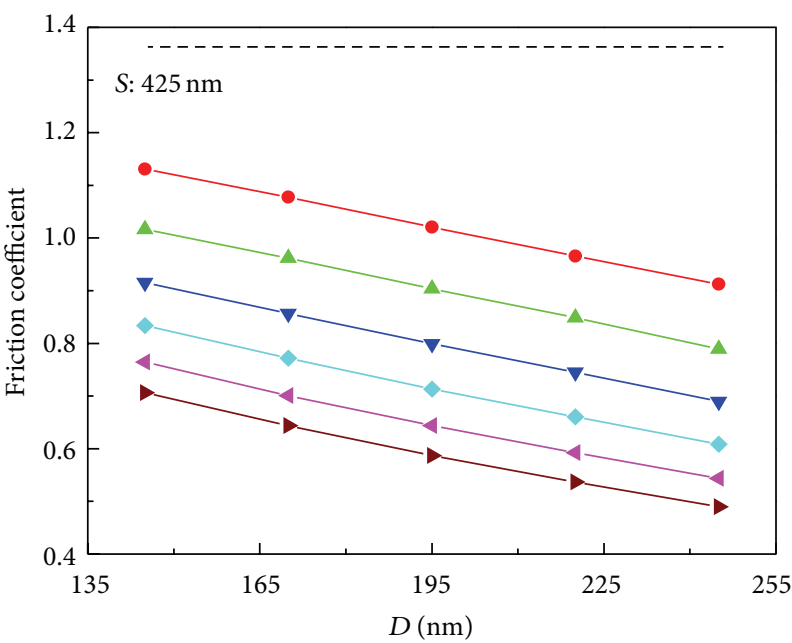

$$
\begin{aligned}
& -- \text { Without pores } \\
& --H=50 \mathrm{~nm} \\
& -\triangle-H=100 \mathrm{~nm} \\
& -\nabla-H=150 \mathrm{~nm}
\end{aligned}
$$

(d)

FIGURE 6: Friction coefficient at different pore diameters and depths of Coscinodiscus sp.: (a) at interval of $350 \mathrm{~nm}$, (b) at interval of $375 \mathrm{~nm}$, (c) at interval of $400 \mathrm{~nm}$, and (d) at interval of $425 \mathrm{~nm}$.

For the Coscinodiscus sp. frustule, its force equilibrium equation is expressed as

$$
\nabla \cdot\left(\sigma_{s}\right)+\rho_{s} f_{s}=\rho_{s} \ddot{d}_{s},
$$

where $\sigma_{s}, f_{s}$, and $\ddot{d}_{s}$ are the stress, body force, and acceleration vectors of the Coscinodiscus sp. frustule in the $x, y$, and $z$ directions, respectively. $\rho_{s}$ is the diatom frustule density.

At the interface between the Coscinodiscus sp. frustule and water, the stress equilibrium and displacement compatibility conditions should be satisfied simultaneously; that is,

$$
\begin{gathered}
\bar{\tau}_{f} \cdot \bar{n}_{f}=\bar{\tau}_{s} \cdot \bar{n}_{s}, \\
\bar{d}_{f}=\bar{d}_{s},
\end{gathered}
$$

where $\underline{\tau}_{f}$ and $\underline{\tau}_{s}$ separately denote the stresses of the water and Coscinodiscus sp. frustule at the interface between them, and their corresponding unit normal vectors are denoted by $n_{f}$ and $n_{s}$, respectively. $\underline{d}_{f}$ and $\underline{d}_{s}$ denote displacements of the water and Coscinodiscus sp. frustule at the interface, respectively.

It should be pointed out that (1)-(3) need to be discretized into algebraic equations and then are solved with FSI method at a grid system. For (1) and (2), they are solved for the water velocity and it pressure and so forth by simple algorithm.

According to the obtained pressure, (3) and (4) are computed for getting the stress and displacement of the frustule. For this, the finite element method is usually employed due to the complexity in the porous frustule of the diatom, 


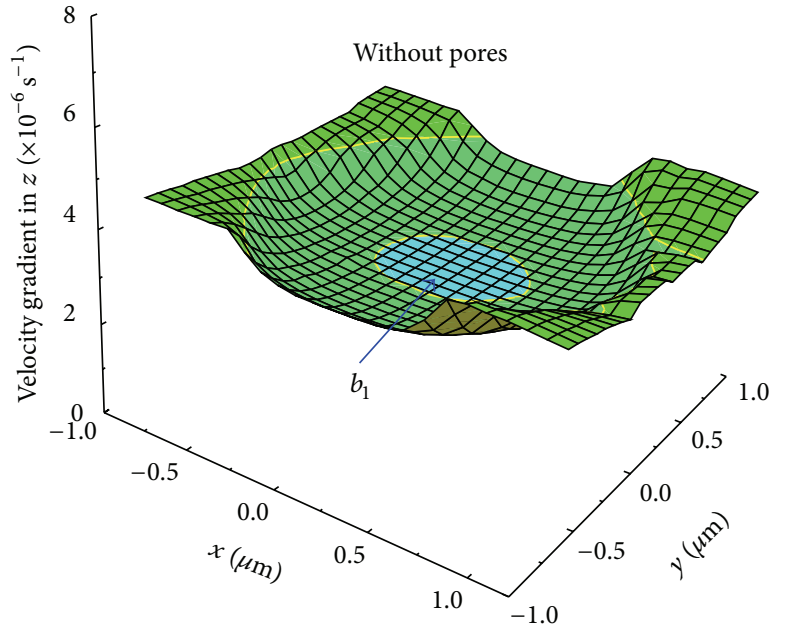

(a)

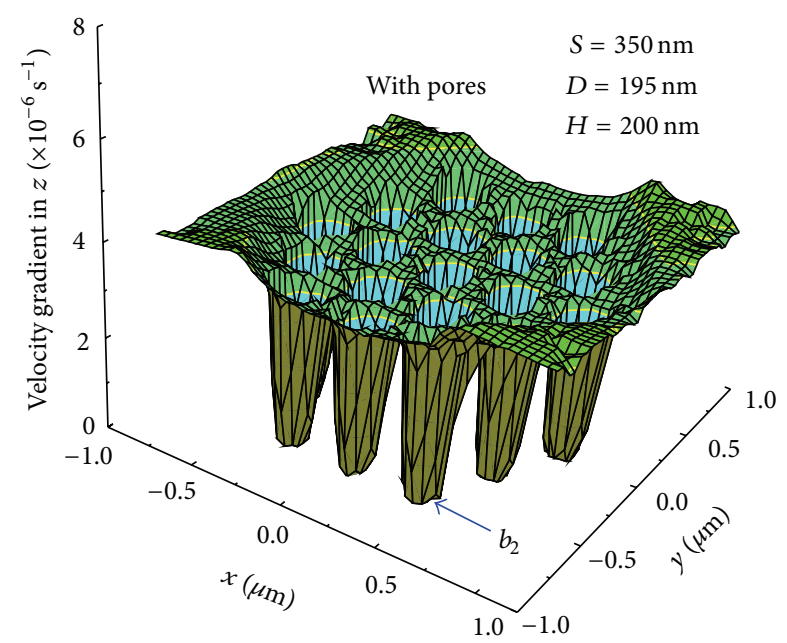

(b)

FIgURE 7: Velocity gradients of Coscinodiscus sp. frustules with and without pores: (a) without pores and (b) with pores.

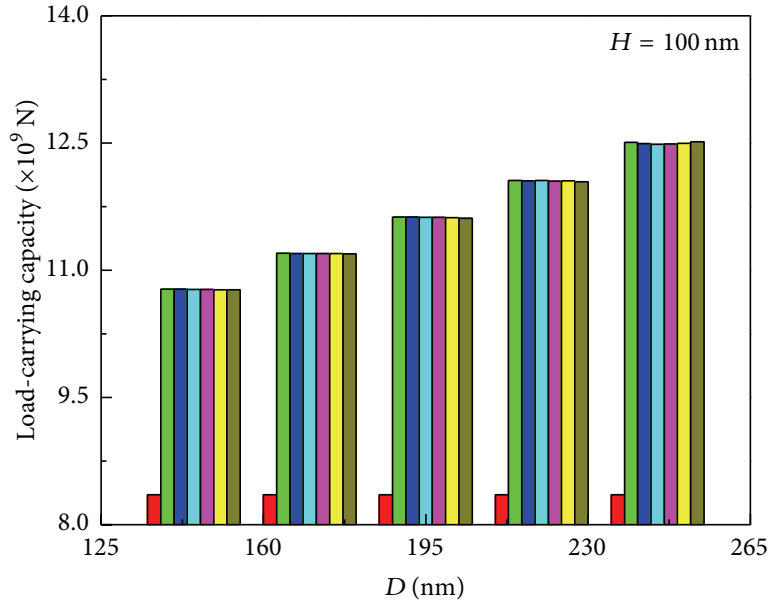

(a)



(c)

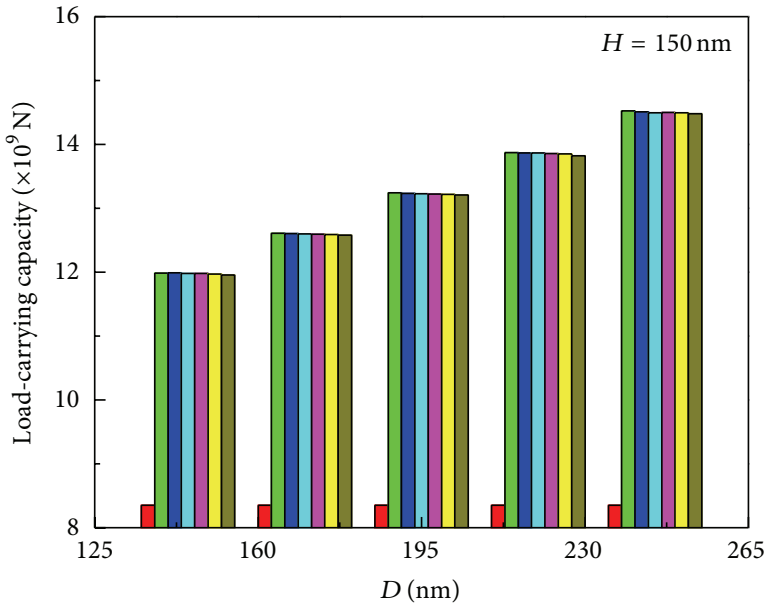

(b)

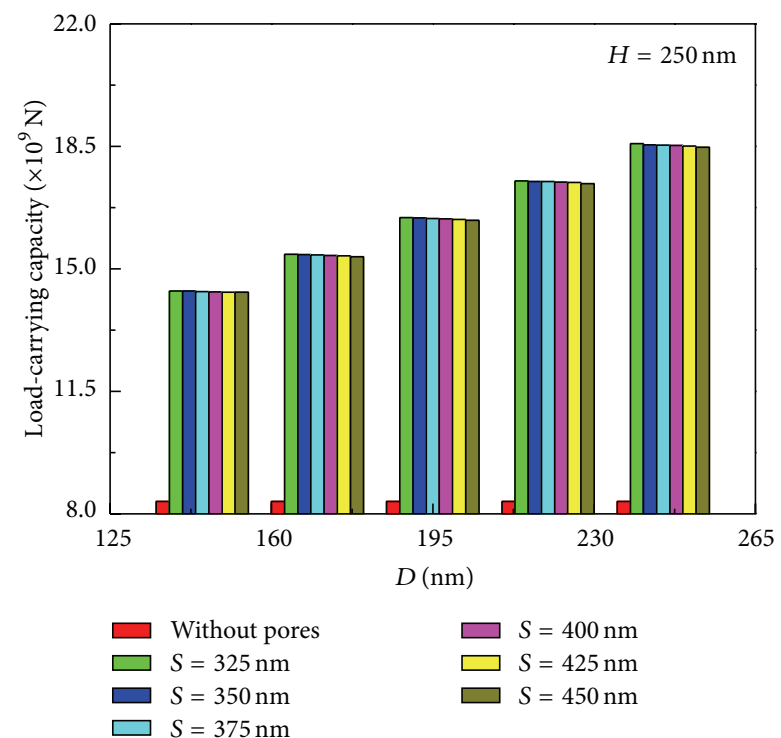

(d)

FIGURE 8: Load-carrying capacities at different intervals of pore: (a) at depth of $100 \mathrm{~nm}$, (b) at depth of $150 \mathrm{~nm}$, (c) at depth of $200 \mathrm{~nm}$, and (d) at depth of $250 \mathrm{~nm}$. 


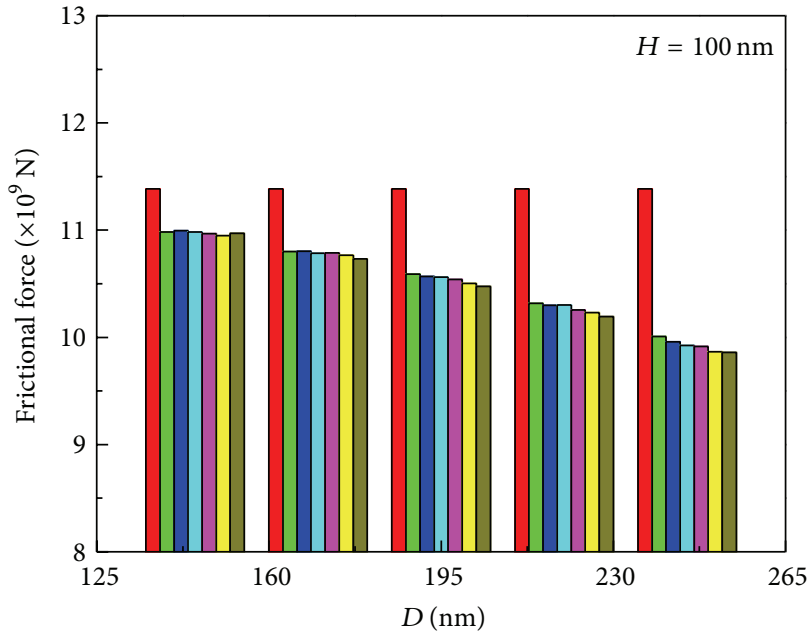

(a)

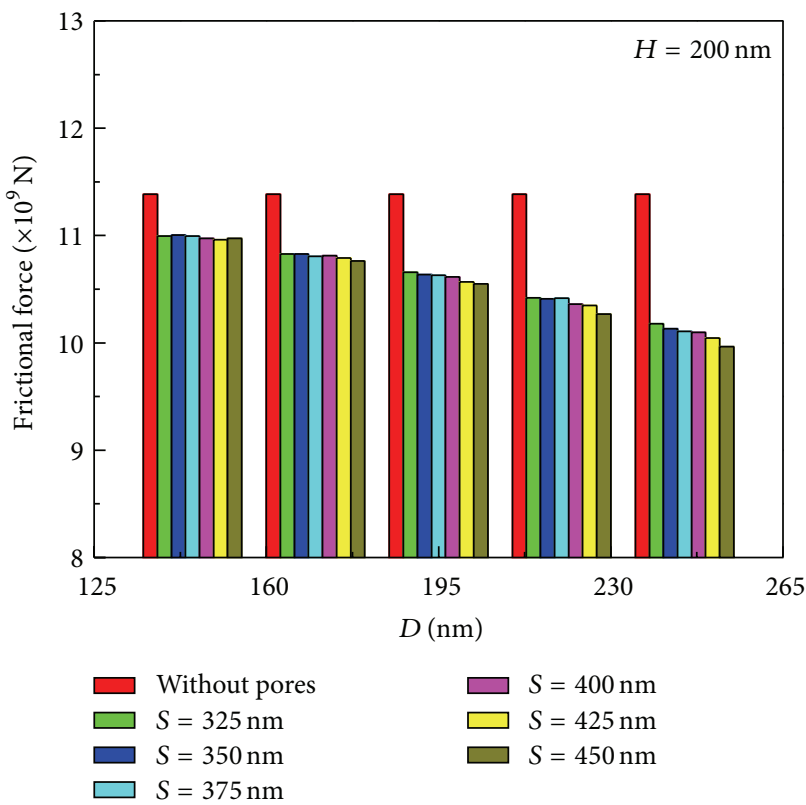

(c)

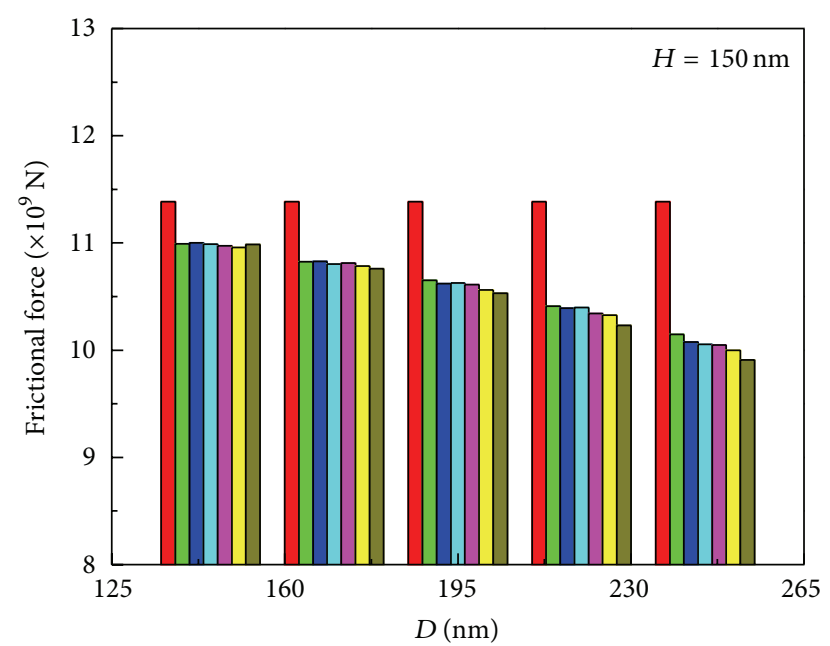

(b)

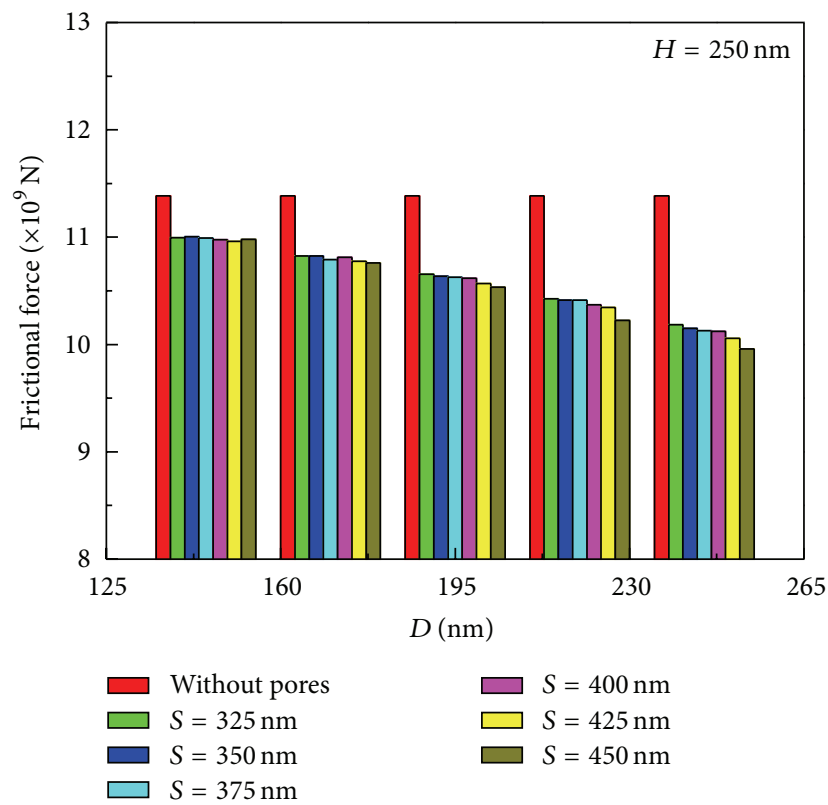

(d)

FiguRE 9: Frictional forces at different intervals of pore: (a) at depth of $100 \mathrm{~nm}$, (b) at depth of $150 \mathrm{~nm}$, (c) at depth of $200 \mathrm{~nm}$, and (d) at depth of $250 \mathrm{~nm}$.

although there are other efficient methods for computing solid performances such as FFT one [21-23]. When the displacement is obtained, it, as boundary input, is transmitted to (1) and (2) and then repeat the above solution process until the given convergent standards are met. This process is accomplished by the CFX, FEA, and ANSYS-Multifield solvers in the commercial software ANSYS14.5 version.

Once the water pressure is achieved according to (1)(4), the load-carrying capacity (i.e., the ability to resist water pressure) for the Coscinodiscus sp. frustule can be computed by integrating the pressure over the interface; that is,

$$
W=\iint_{A} p d x d y
$$

where $A$ is the interface area.
The frictional force can be calculated by the following integral expression:

$$
F_{f}=-\iint_{A} \mu \frac{\partial v_{x}}{\partial z} d x d y,
$$

where $v_{x}$ denotes the relative velocity between the water and Coscinodiscus sp. frustule in the $x$ direction.

With the calculated $W$ and $F_{f}$, the friction coefficient can be obtained by

$$
f=\frac{F_{f}}{W} .
$$

In what follows, the tribological performances, mainly the load-carrying capacity, frictional force, and friction coefficient, for the Coscinodiscus sp. frustule will be analyzed. 


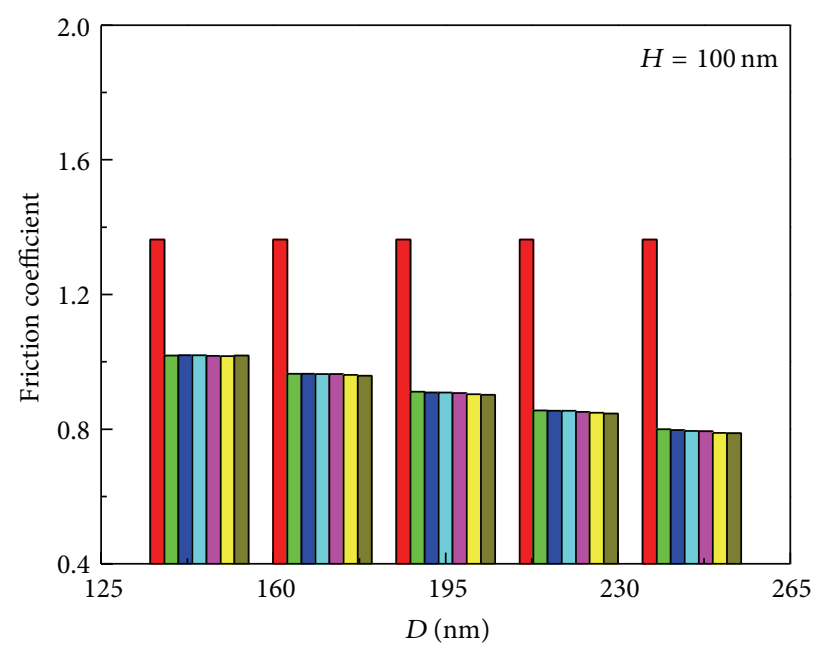

(a)

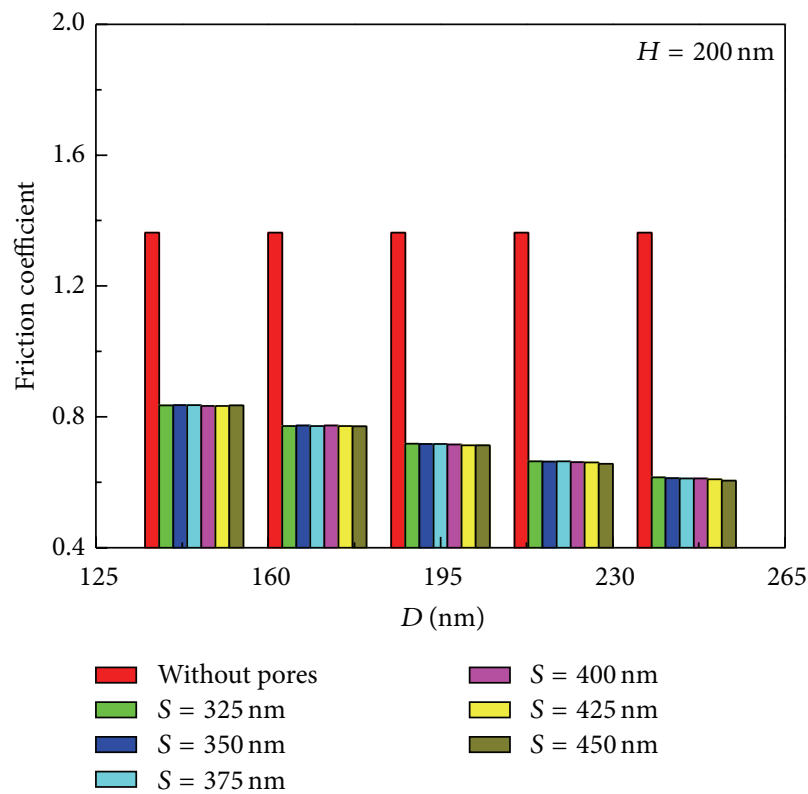

(c)

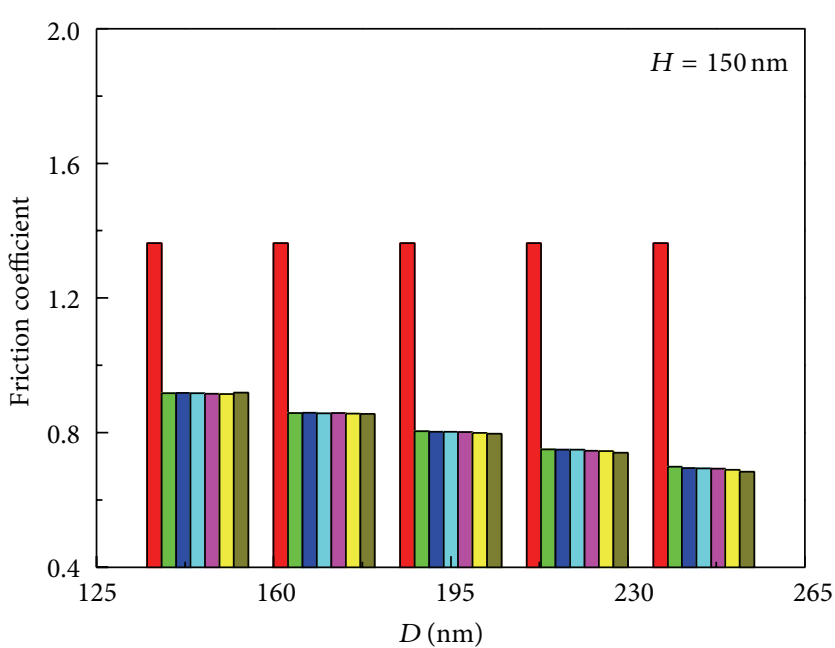

(b)

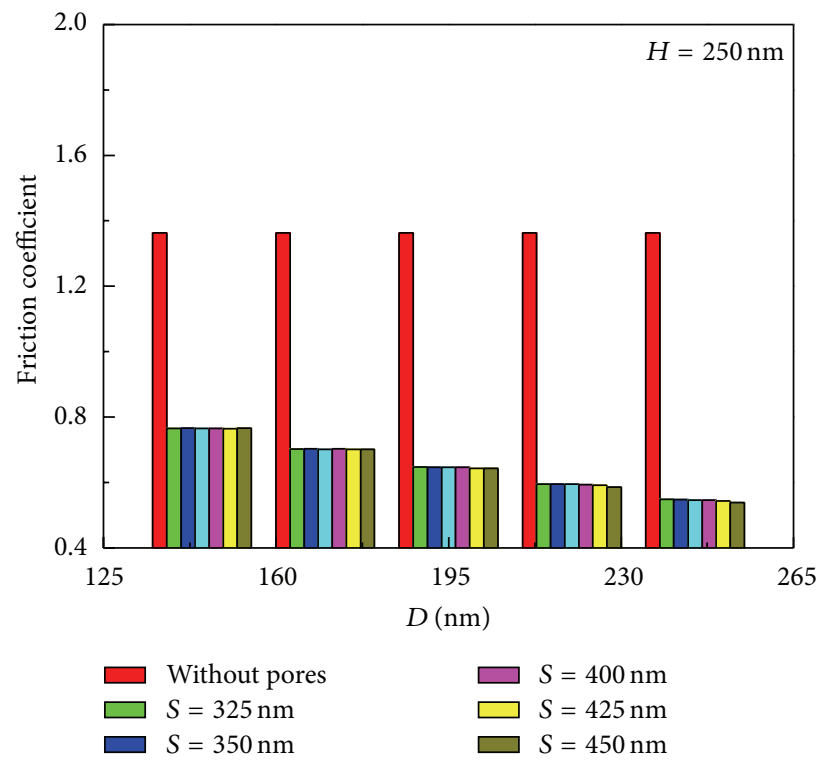

(d)

FIGURE 10: Friction coefficient at different intervals of pore: (a) at depth of $100 \mathrm{~nm}$, (b) at depth of $150 \mathrm{~nm}$, (c) at depth of $200 \mathrm{~nm}$, and (d) at depth of $250 \mathrm{~nm}$.

\section{Results and Discussions}

4.1. Check of Mesh. In the simulation, numerical results may be affected by the used mesh density in discretizing the imitated Coscinodiscus sp. frustule. Therefore, it is necessary to conduct an analysis of the mesh sensitivity. This analysis is made under the condition of the pore diameter $D$ of $195 \mathrm{~nm}$, pore depth $H$ of $200 \mathrm{~nm}$, and the $375 \mathrm{~nm}$ interval $S$ between closely adjacent pores. Meanwhile, the water velocity of $2 \mathrm{~m} / \mathrm{s}$ and the Coscinodiscus sp. frustule velocity of $1 \mathrm{~m} / \mathrm{s}$ are employed. Based on the above parameters, the maximum water pressures $P_{\max }$ at different mesh sizes are calculated. The calculation shows that when the mesh size is $50 \mathrm{~nm}$, the relative percentage difference (Dif.\%) of $P_{\max }$ is $1.08 \%$. In this case, if the mesh density continues to be added, the difference continues to become smaller. Therefore, the critical mesh size of $50 \mathrm{~nm}$ is chosen for the following simulation about tribological performances for the porous structure of the Coscinodiscus sp. frustule.

4.2. Geometry Sizes and Velocity Effects. Figure 3 gives the load-carrying capacity $(W)$ as a function of pore diameter (D) of the Coscinodiscus sp. frustule with varying pore depth $(H)$ and interval $S$ between the pores. In each subfigure, the dotted line represents the $W$ value for the nonporous frustule. As shown in these subfigures, Coscinodiscus sp. frustule has the $W$ value larger than that for the nonporous frustule in the same $D$. Moreover, $W$ increases with increasing $H$ or $D$. This increment can be explained by the water film 


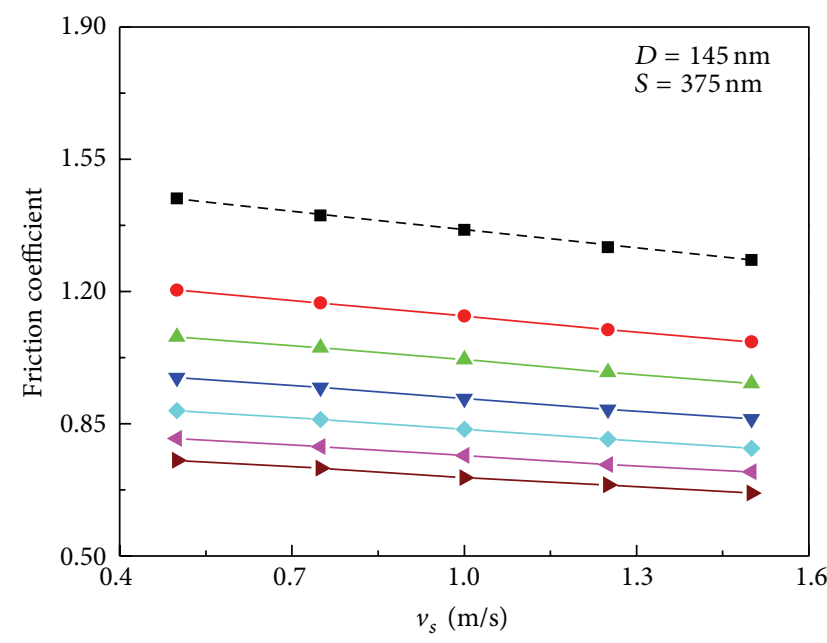

(a)

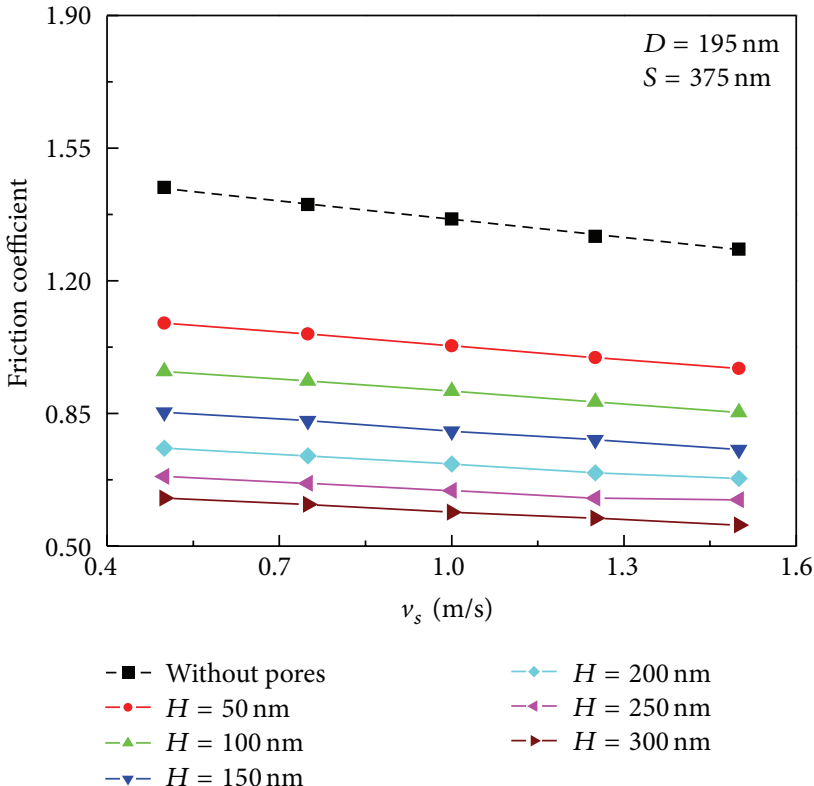

(c)



(b)

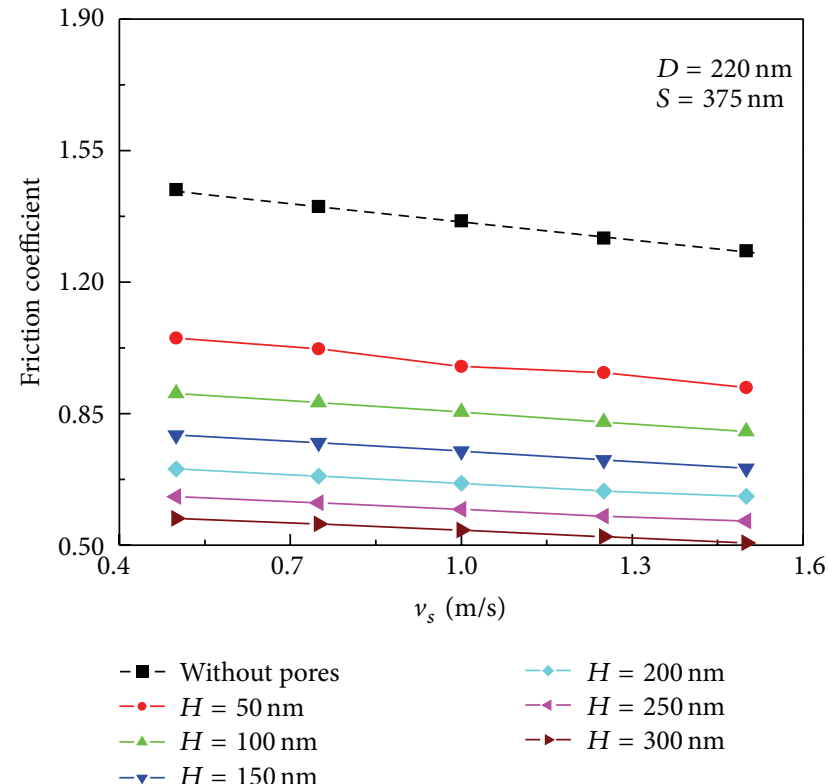

(d)

Figure 11: Friction coefficient at different speeds of Coscinodiscus sp. frustule: (a) at diameter of $145 \mathrm{~nm}$, (b) at diameter of $170 \mathrm{~nm}$, (c) at diameter of $195 \mathrm{~nm}$, and (d) at diameter of $220 \mathrm{~nm}$.

pressures applied on the frustule, as illustrated in Figures 4(a) and 4(b). Figure 4(a) exhibits the pressure without the pore consideration, while that for the Coscinodiscus sp. frustule is presented in Figure 4(b). Compared with the relative smooth pressure distribution with the smaller amplitude in Figure 4(a), there exist many pressure peaks for the Coscinodiscus sp. structure shown in Figure 4(b), which is due mainly to the phenomenon that every pore acts as an oil reservoir [24]. Thus, it is understandable that the loadcarrying capacity of the latter is larger than that for the former according to (5). The above discrepancy can be observed by the comparison between the pressures marked off with point $a_{1}$ in Figure 4(a) and point $a_{2}$ in Figure 4(b).

Friction is an important care in tribology researches. Figures 5 and 6 separately exhibit the discrepancy in the frictional force $(F)$ and friction coefficient $(f)$ between the Coscinodiscus sp. frustule and its corresponding nonporous structure. In the two figures, the dotted lines represent $F$ and $f$ for the nonporous frustule, respectively. Opposite to the variation trend of $W$ in Figure 3, both $F$ and further $f$ for the porous structure decrease compared with values of the nonporous structure, if $D$ or $H$ is fixed, which is consistent with the experimental results from Gebeshuber and Crawford [16]. This can be explained with the velocity gradient. Figure 7 (a) exhibits the velocity gradient for the nonporous structure, while it fluctuates significantly near the pores for the Coscinodiscus sp. frustule (e.g., marked off with $b_{2}$ ) in Figure 7(b). Meanwhile, it can be seen from Figures 7 (a) and 7(b) that the existence of the porous structure results in the decrement in the amplitude for the velocity gradient. 
In this case, the frictional force for the porous frustule decreases according to (6) and further its friction coefficient decreases because of its enhanced load-carrying capacity, which can be observed from (7).

The influences of the interval $S$ on the load-carrying capacity, frictional force, and friction coefficient of the Coscinodiscus sp. frustule with varying pore diameter $D$ and pore depth $H$ are presented in Figures 8, 9, and 10, respectively. As shown in these figures, the existence of the pores results in the larger load-carrying capacity, smaller frictional force, and further smaller friction coefficient, if $D$ and $S$ are fixed simultaneously. Meanwhile, in the cases of geometry sizes given, $S$ has little effect on the load-carrying capacity and friction coefficient.

The above results were obtained at the Coscinodiscus sp. frustule velocity $v_{s}=1 \mathrm{~m} / \mathrm{s}$. To explore $v_{s}$ effects on tribological performances, keep the water velocity $v_{f}$ equal to $2 \mathrm{~m} / \mathrm{s}$ and interval $S$ at $375 \mathrm{~nm}$. Figure 11 gives the friction coefficients as a function of $v_{s}$ with varying pore depth $H$. As shown in Figure 11, the friction coefficients of the Coscinodiscus sp. frustules are less than those of the nonporous structure frustules, which is consistent with the conclusion of Figures 6 and 10. It should be pointed out that the bigger friction coefficients exhibited in the present study are due mainly to the comparatively small load-carrying capacity of the water because of its parallel flow through the Coscinodiscus sp. frustule.

In this case, the frictional force and load-carrying capacity separately exhibit a relative reduction and increment if the frustule pores are considered, omitted here.

\section{Summary}

Take, for example, the Coscinodiscus sp. moving in the water; tribological performances of the elaborate pores on the diatom frustule were investigated with FSI method. The simulation shows that these pores can enhance the loadcarrying capacity for the diatom to resist the water pressure. And they also contribute to the reduction in the frictional force between the diatom frustule and water and further friction coefficient. Within the range of geometry sizes used, the larger pore diameter or depth will help to improve the load-carrying capacity but reduce the friction coefficient. This porous structure for the diatom frustule is promising in engineering applications.

\section{Conflict of Interests}

The authors declare that there is no conflict of interests regarding the publication of this paper.

\section{Acknowledgments}

The authors would like to express their gratitude for the support from the Natural Science Foundation of China (Contract no. 51375509), the Fundamental Research Funds for the Central Universities of China (Contract no. CDJZR12248801), and Program for New Century Excellent Talents of Ministry of Education of China (Project no. NCET-10-0881).

\section{References}

[1] D. G. Mann and S. J. M. Droop, "Biodiversity, biogeography and conservation of diatoms," Hydrobiologia, vol. 336, no. 1-3, pp. 19-32, 1996.

[2] M. B. Dickerson, K. H. Sandhage, and R. R. Naik, "Protein- and peptide-directed syntheses of inorganic materials," Chemical Reviews, vol. 108, no. 11, pp. 4935-4978, 2008.

[3] A. Bozarth, U. G. Maier, and S. Zauner, "Diatoms in biotechnology: modern tools and applications," Applied Microbiology and Biotechnology, vol. 82, no. 2, pp. 195-201, 2009.

[4] D. Losic, J. G. Mitchell, and N. H. Voelcker, "Diatomaceous lessons in nanotechnology and advanced materials," Advanced Materials, vol. 21, no. 29, pp. 2947-2958, 2009.

[5] Y. N. Fang, V. W. Chen, Y. Cai et al., "Biologically enabled syntheses of freestanding metallic structures possessing subwavelength pore arrays for extraordinary (surface plasmonmediated) infrared transmission," Advanced Functional Materials, vol. 22, no. 12, pp. 2550-2559, 2012.

[6] D. Y. Zhang, Y. Wang, and J. Cai, "Bio-manufacturing based on the micro and nano structures of diatom," Chinese Science Bulletin, vol. 57, no. 24, pp. 2249-2263, 2012.

[7] N. Kröger, "Prescribing diatom morphology: toward genetic engineering of biological nanomaterials," Current Opinion in Chemical Biology, vol. 11, no. 6, pp. 662-669, 2007.

[8] J. Michels, J. Vogt, and S. N. Gorb, “Tools for crushing diatomsopal teeth in copepods feature a rubber-like bearing composed of resilin," Scientific Reports, vol. 2, Article ID 465, 2012.

[9] D. Losic, R. J. Pillar, T. Dilger, J. G. Mitchell, and N. H. Voelcker, "Atomic force microscopy (AFM) characterisation of the porous silica nanostructure of two centric diatoms," Journal of Porous Materials, vol. 14, no. 1, pp. 61-69, 2007.

[10] C. E. Hamm, R. Merkel, O. Springer et al., "Architecture and material properties of diatom shells provide effective mechanical protection," Nature, vol. 421, no. 6925, pp. 841-843, 2003.

[11] N. Almqvist, Y. Delamo, B. L. Smith et al., "Micromechanical and structural properties of a pennate diatom investigated by atomic force microscopy," Journal of Microscopy, vol. 202, no. 3, pp. 518-532, 2001.

[12] D. C. Jang, L. R. Meza, F. Greer, and J. R. Greer, "Fabrication and deformation of three-dimensional hollow ceramic nanostructures," Nature Materials, vol. 12, no. 10, pp. 893-898, 2013.

[13] D. Sen and M. J. Buehler, "Structural hierarchies define toughness and defect-tolerance despite simple and mechanically inferior brittle building blocks," Scientific Reports, vol. 1, article 35, pp. 1-9, 2011.

[14] A. M. Young, L. Karp-Boss, P. A. Jumars, and E. N. Landis, "Quantifying diatom aspirations: mechanical properties of chain-forming species," Limnology and Oceanography, vol. 57, no. 6, pp. 1789-1801, 2012.

[15] A. P. Garcia, D. Sen, and M. J. Buehler, "Hierarchical silica nanostructures inspired by diatom algae yield superior deformability, toughness, and strength," Metallurgical and Materials Transactions A: Physical Metallurgy and Materials Science, vol. 42, no. 13, pp. 3889-3897, 2011.

[16] I. C. Gebeshuber and R. M. Crawford, "Micromechanics in biogenic hydrated silica: Hinges and interlocking devices in diatoms," Proceedings of the Institution of Mechanical Engineers 
J: Journal of Engineering Tribology, vol. 220, no. 8, pp. 787-796, 2006.

[17] I. C. Gebeshuber, H. Stachelberger, and M. Drack, "Diatom bionanotribology-biological surfaces in relative motion: their design, friction, adhesion, lubrication and wear," Journal of Nanoscience and Nanotechnology, vol. 5, no. 1, pp. 79-87, 2005.

[18] K. Toyoda, D. M. Williams, J. Tanaka, and T. Nagumo, "Morphological investigations of the frustule, perizonium and initial valves of the freshwater diatom Achnanthes crenulata Grunow (Bacillariophyceae)," Phycological Research, vol. 54, no. 3, pp. 173-182, 2006.

[19] M. de Stefano and L. de Stefano, "Nanostructures in diatom frustules: functional morphology of valvocopulae in cocconeidacean monoraphid taxa," Journal of Nanoscience and Nanotechnology, vol. 5, no. 1, pp. 15-24, 2005.

[20] I. C. Gebeshuber, J. H. Kindt, J. B. Thompson et al., "Atomic force microscopy study of living diatoms in ambient conditions," Journal of Microscopy, vol. 212, no. 3, pp. 292-299, 2003.

[21] K. Zhou, L. M. Keer, Q. J. Wang et al., "Interaction of multiple inhomogeneous inclusions beneath a surface," Computer Methods in Applied Mechanics and Engineering, vol. 217-220, pp. 2533, 2012.

[22] K. Zhou, L. M. Keer, and Q. J. Wang, "Semi-analytic solution for multiple interacting three-dimensional inhomogeneous inclusions of arbitrary shape in an infinite space," International Journal for Numerical Methods in Engineering, vol. 87, no. 7, pp. 617-638, 2011.

[23] W. W. Chen, K. Zhou, L. M. Keer, and Q. J. Wang, "Modeling elasto-plastic indentation on layered materials using the equivalent inclusion method," International Journal of Solids and Structures, vol. 47, no. 20, pp. 2841-2854, 2010.

[24] F. M. Meng, R. Zhou, T. Davis et al., "Study on effect of dimples on friction of parallel surfaces under different sliding conditions," Applied Surface Science, vol. 256, no. 9, pp. 2863$2875,2010$. 

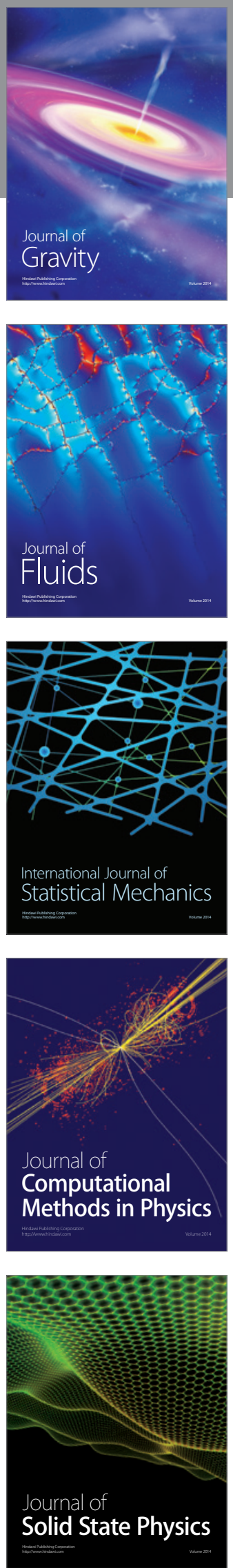

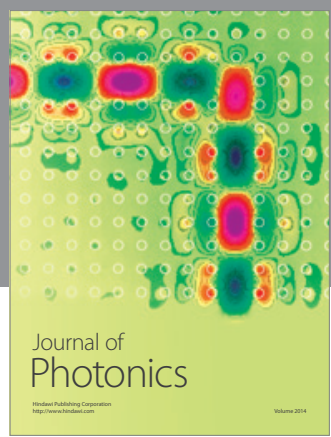

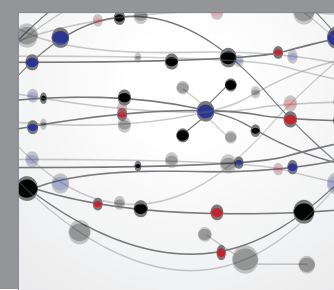

The Scientific World Journal



Soft Matter


Submit your manuscripts at

http://www.hindawi.com
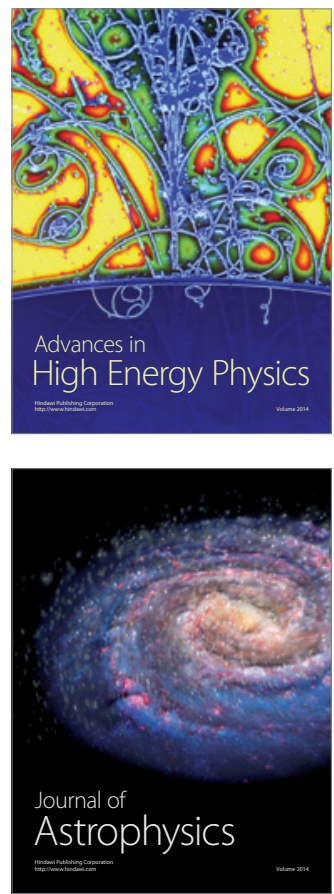
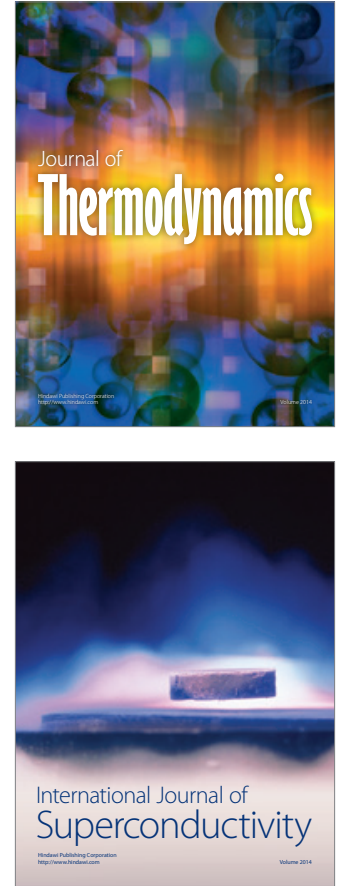
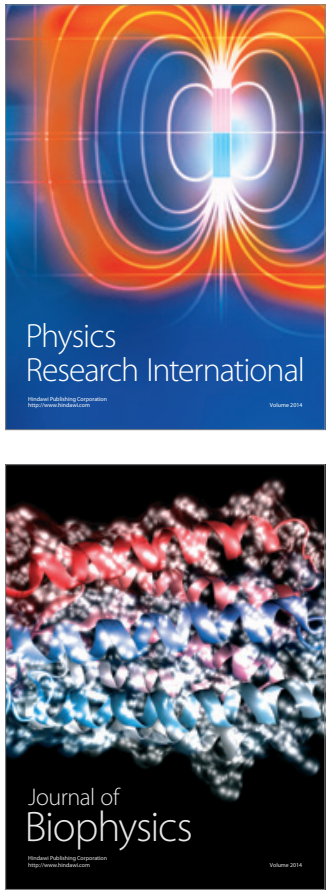
